\title{
Repeated Non-Invasive Limb Ischemic Preconditioning Confers Cardioprotection Through PKC-E/STAT3 Signaling in Diabetic Rats
}

\author{
Chunyan Wang ${ }^{\mathrm{a}, \mathrm{b}}$ Haobo Lia,c Sheng Wang ${ }^{\mathrm{d}}$ Xiaowen Mao ${ }^{\mathrm{a}}$ Dan Yan ${ }^{\mathrm{a}}$ \\ Stanley S. Wong ${ }^{a}$ Zhengyuan Xia ${ }^{a, c} \quad$ Michael G. Irwin ${ }^{a}$
}

aDepartment of Anesthesiology, The University of Hong Kong, Hong Kong SAR, bDepartment of Anesthesiology, Shenzhen People's Hospital and Shenzhen Anesthesiology Engineering Center, the Second Clinical Medical College of Jinan University, Shenzhen, 'State Key Laboratory of Pharmaceutical Biotechnology, The University of Hong Kong, Hong Kong, dDepartment of Anesthesiology, Guangdong Cardiovascular Institute, Guangdong General Hospital, Guangdong Academy of Medical Sciences, Guangdong, China

\section{Key Words}

Repeated non-invasive limb ischemic preconditioning - Myocardial ischemia injury $•$ PKC- $\varepsilon$ • STAT3 - Diabetes

\begin{abstract}
Background/Aims: Protein kinase C(PKC)- $\varepsilon$ activation is a mechanism of preconditioning cardioprotection but its role in repeated non-invasive limb ischemic preconditioning (rNLIP) mediated cardioprotection against myocardial ischemia/reperfusion (I/R) injury in diabetes is unknown. Methods: Eight-week streptozotocin-induced diabetic and non-diabetic SpragueDawley rats were subjected to I/R without or with rNLIP. In vitro, $\mathrm{H} 9 \mathrm{C} 2$ cells were cultured with high glucose $(H G)$ and subjected to hypoxia/re-oxygenation $(H / R)$ without or with PKC- $\varepsilon$ or STAT3 gene knock-down in the absence or presence of remote time hypoxia preconditioning (HPC). Results: Diabetic rats displayed larger post-ischemic myocardial infarct size and higher troponin-I release with concomitant cardiac PKC- $\varepsilon$ overexpression and activation manifested as increased membrane translocation, while phosphorylated STAT3 ( $p$-STAT3) and Akt ( $p$-Akt) were lower compared to non-diabetic rats (all $P<0.05$ ). rNLIP reduced infarct size in both nondiabetic and diabetic rats. rNLIP reduced post-ischemic cardiac PKC- $\varepsilon$ activation in diabetic while increased PKC- $\varepsilon$ activation in non-diabetic rats, resulting in increased cardiac p-STAT3 and p-Akt. In $\mathrm{H} 9 \mathrm{C} 2$ cells, HG increased PKC- $\varepsilon$ expression and exacerbated post-H/R injury, accompanied with reduced p-STAT3 and p-Akt, which were all reverted by HPC. These HPC protective effects were abolished by either PKC- $\varepsilon$ or STAT3 gene knock-down, except that PKC- $\varepsilon$ gene knock-down reverted HG and H/R-induced reduction of p-STAT3. Conclusion:
\end{abstract}

\section{KARGER}




\section{Cellular Physiology Cell Physiol Biochem 2018;45:2107-2121 \\ \begin{tabular}{ll|l} 
and Biochemistry Published online: March 12, 2018 & $\begin{array}{l}\text { (c) } 2018 \text { The Author(s). Published by S. Karger AG, Basel } \\
\text { www.karger.com/cpb }\end{array}$ \\
\hline
\end{tabular} \\ Wang et al.: Repeated Non-Invasive Limb Ischemic Preconditioning Confers Protection \\ in Diabetes}

rNLIP attenuates diabetic heart I/R injury by mitigating HG-induced PKC- $\varepsilon$ overexpression and, subsequently, activating STAT3.

(C) 2018 The Author(s)

Published by S. Karger AG, Basel

\section{Introduction}

Myocardial ischemia, post-ischemic myocardial injury and heart failure are leading causes of death worldwide, particularly in patients with diabetes [1]. Paradoxically, re-establishment of blood flow to ischemic myocardium may cause further damage, a phenomenon referred to as ischemia/reperfusion injury (I/RI) [2-4]. Brief episodes of ischemia intermitted with reperfusion before prolonged ischemia can reduce post-ischemic myocardial infarct size, a phenomenon termed ischemic preconditioning (IPC) [5]. IPCmediated protection of one organ or tissue (even peripheral muscle) also protects distant organs/tissues (e.g. heart or spinal cord) from ischemic injury through a different signaling pathway [6,7], and this phenomenon is termed remote ischemic preconditioning (RIPC) [8]. Interestingly, brief cycles of non-invasive limb ischemia and reperfusion (NLIP), a type of RIPC, has been proven to be cardioprotective in experimental settings which is easy to operate $[9,10]$. However, NLIP is less efficacious in certain pathological states, such as diabetes, senescence and obesity. Interestingly, we showed that application of 3 cycles of NLIP per day for 3 days (repeated NLIP, rNLIP) attenuated myocardial I/RI in diabetic rats [11-13], suggesting that, in order to confer cardioprotection under pathological conditions, the threshold of NLIP should be increased. However, the mechanism whereby rNLIP may confer cardioprotection in diabetes is unclear.

Activation of the signal transducer and activator of transcription 3 (STAT3) is critical for NLIP to confer cardioprotection [14] but cardiac STAT3 is reduced in diabetes [15], which might reflect why diabetic hearts are less responsive to NLIP [16]. We previously found that rNLIP conferred cardioprotection in diabetic rats [11] whose cardiac STAT3 was initially reduced [15]. It is possible, therefore, that enhancing cardiac STAT3 activation may be a mechanism to restore rNLIP in diabetes. However, the mechanism governing STAT3 activation in rNLIP, especially in diabetic hearts, is unclear.

Besides STAT3, activation of the epsilon isoform of protein kinase C (PKC- $\varepsilon$ ) is crucial for IPC and NLIP to confer protection against myocardial I/RI given that PKC- $\varepsilon$ knock-out cancels IPC [17] and inhibition of PKC- $\varepsilon$ membrane translocation blocked NLIP-mediated cardioprotection [18]. The role of PKC in cardioprotecton is contentious [19], being either isoform specific or dependent on the extent of its activation. PKC- $\varepsilon$ is essential for IPC to activate STAT3 at site Ser727 and confer its late phase cardioprotection $[17,20]$. Activation of PKC- $\varepsilon$ induces STAT3 phosphorylation, while PKC- $\varepsilon$ knockdown reduces STAT3 phosphorylation [21]. In diabetes, PKC- $\varepsilon$ is over-expressed and activated [22] contributing to the onset of hyperinsulinemia, hyperglycaemia [23] and cardiac remodelling in type-2 diabetic mice [24].On the other hand, we recently showed that cardiac STAT3 is reduced in diabetic rats [25]. However, the potential causal link between PKC- $\varepsilon$ and STAT3 in diabetes has not been explored. In particular, whether or not over-activation of cardiac PKC- $\varepsilon$ in diabetes is responsible for the loss of sensitivity of the diabetic heart to rNLIP cardioprotection is unknown.

Therefore, we hypothesized that over-activation of PKC- $\varepsilon$, by down-regulating cardiac STAT3, renders the diabetic heart susceptible to myocardial I/R injury and not responsive to rNLIP cardioprotection.

\section{Materials and Methods}

Induction of diabetes

Male Sprague-Dawley rats (250 g, 6-8 weeks) obtained from the Laboratory Animal Unit (The University of Hong Kong) were used in this study. Diabetes were induced by single dose $(65 \mathrm{mg} / \mathrm{kg})$ streptozotocin 


\section{Cellular Physiology Cell Physiol Biochem 2018;45:2107-2121 \begin{tabular}{ll|l} 
and Biochemistry Published online: March 12, 2018 & $\begin{array}{l}\text { (C) } 2018 \text { The Author(s). Published by S. Karger AG, Basel } \\
\text { www.karger.com/cpb }\end{array}$
\end{tabular} \\ Wang et al.: Repeated Non-Invasive Limb Ischemic Preconditioning Confers Protection in Diabetes}

(STZ) (Sigma-Aldrich, St. Louis, MO) injection via tail vein as described [26, 27]. Rats were housed in the Laboratory Animal Service Center (University of Hong Kong) and received standard care in accordance with the principles of Animal Care of the University of Hong Kong. The experimental protocols were approved by the committee on the Use of Live Animals in Teaching and Research (CULATR). The I/R and rNLIP protocol and grouping ( $n=6$ rats per group) were described in the diagram below (Fig. 1).

In vivo model of myocardial ischemia reperfusion $(I / R)$ and $r N L I P$

Eight weeks after diabetes induction, rNLIP was implemented by applying 3 cycles of 5 - minute occlusion/5- minute reperfusion in a unilateral hindlimb daily for 3 days. The unilateral right hindlimb was selected to apply rNLIP because it is

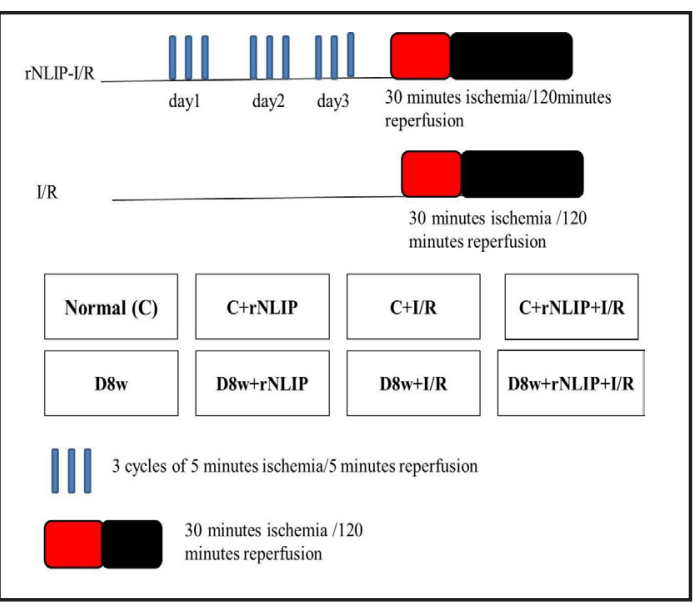

Fig. 1. In vivo experimental protocols. I/R: ischemia/ reperfusion; rNLIP: repeated non-invasive limb ischemia preconditioning. Normal(C): non-diabetic control rats; D8w: 8 weeks diabetic rats. easier to tie up and closer to the heart relative to the left hindlimb. Twenty-four hours after the completion of rNLIP, the rats were subjected to myocardial I/ RI. Rats in the respective subgroups were anesthetized using phenobarbital sodium; ischemia was achieved by occluding the left anterior descending (LAD) artery for 30 minutes followed by reperfusion for 2 hours as described [28]. Infarct size (IS) was assessed using TTC (1\% 2, 3, 5-triphenyltetrazolium chloride) staining and expressed as a percentage of the anatomic area at risk (AAR) [29, 30]. Five percent Evans Blue was injected through the right jugular vein to mark the normal region of the left ventricle (LV) and to calculate AAR. At the completion of the experiments, the rats were euthanized with overdose pentobarbital injection, and the hearts were quickly removed and cut into 5 slices of $1 \mathrm{~mm}$ cross-sections, followed by incubation in 1\% TTC in PBS at room temperature for 20 minutes. The slices were then fixed with $10 \%$ formalin overnight. Parts of the LV tissues were immediately frozen in liquid nitrogen until processed for Western Blotting analysis.

In vitro models of cardiac $H 9 C 2$ cells hypoxia reoxygenation $(H / R)$ and remote time hypoxic preconditioning (HPC)

Embryonic rat cardiac H9C2 cells were maintained in Dulbecco's modified Eagle's medium (DMEM) containing $10 \% \mathrm{FBS}$ in a humidified atmosphere $\left(5 \% \mathrm{CO}_{2}\right)$ at $37^{\circ} \mathrm{C}$. To mimic high glucose (HG) condition in diabetes, high D-glucose $(25 \mathrm{mM})$ was added to the medium to make the final glucose concentration at $30 \mathrm{mM}$, and the glucose concentration in normal medium (glucose: $5.5 \mathrm{mM}$ ) was used as normal glucose control group. Mannitol/glucose was added (19.5mM mannitol plus 5.5mM glucose) for osmotic control.

To partially mimic the in vivo situation in which rNLIP was completed 24 hours before I/R initiation, remote time repeated hypoxic preconditioning (HPC, which was achieved by 3 cycles of 5 minutes hypoxia followed by 5 minutes of re-oxygenation) was completed 24 hours before inducing hypoxic/ re-oxygenation $(\mathrm{H} / \mathrm{R})$ in cultured cardiac H9C2 cells as mentioned below. To verify the effects of HPC on cellular injury and cardiac signaling proteins in the absence of hypoxia/reoxygenation, we also performed the preliminary experiment of HPC alone under NG or HG conditions.

$P K C$ - or STAT3 small interference RNA (siRNA) studies, hypoxia reoxygenation $(H / R)$, and remote time hypoxic preconditioning (HPC) in H9C2 cells

Gene silencing was performed using PKC- $\varepsilon$ siRNA or STAT3 siRNA, control siRNA and transfection reagent, purchased from Santa Cruz Biotechnology (Dallas, Texas, USA) following the manufacturer's instructions. In brief, $2 * 10^{5} \mathrm{H} 9 \mathrm{C} 2$ cells were seeded and maintained in DMEM containing $10 \%$ FBS in a humidified atmosphere $\left(5 \% \mathrm{CO}_{2}\right)$ at $37^{\circ} \mathrm{C}$ and were allowed to reach $60-80 \%$ confluence. Then the cells were transfected with targeted siRNA and control siRNA. Six hours after transfection, normal growth medium was added and the cells were incubated at $37^{\circ} \mathrm{C}$ in a humidified atmosphere $\left(5 \% \mathrm{CO}_{2}\right)$ for 24 


\section{Cellular Physiology Cell Physiol Biochem 2018;45:2107-2121

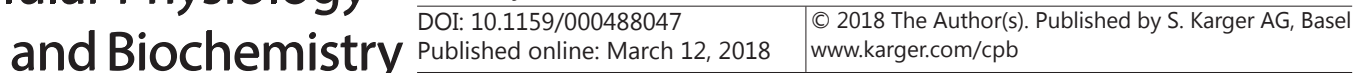 Wang et al.: Repeated Non-Invasive Limb Ischemic Preconditioning Confers Protection \\ in Diabetes}

hours. Then the cells were subjected to 6 hours of hypoxia and 12 hours of re-oxygenation with or without high glucose (30 mM). HPC and hypoxic conditions were performed as described above.

Hypoxic conditions were obtained by equilibrating a humidified plexiglass chamber containing myocytes with $95 \% \mathrm{~N}_{2}$ and $5 \% \mathrm{CO}_{2}$ and confirmed by measuring chamber $\mathrm{O}_{2}$ concentration falling to $0.1 \%$. Re-oxygenation was achieved by exposing cells to room air ( $\mathrm{CO}_{2}$ incubator). Remote time HPC was achieved by 3 cycles of 5 minutes hypoxia followed by 5 minutes of re-oxygenation 24 hours before hypoxic/ reoxygenation (H/R).

Assessment of lactate dehydrogenase ( $\mathrm{LDH}$ ) and Troponin-I (Tn-I) release

After 2 hours of reperfusion (i.e. the completion of the experiment), blood samples were collected from the carotid artery and then centrifuged to separate serum. For H9C2 cells, after H/R, cellular medium was collected and then centrifuged for detection of LDH. LDH and Tn-I are specific markers of tissue damage. Therefore, plasma levels of LDH and Tn-I release as well as level of LDH in cell supernatant were analyzed using a LDH cytotoxicity assay kit (Roche USA) and Tn-I ELISA kit (Cloud-Clone Corp) following the manufacturer's instructions as described.

\section{Determination of mitochondrial membrane potential (MMP) loss}

MMP was an important indicator of cell death. MMP loss was measured using a JC-1 mitochondrial membrane potential kit (Cayman Chemical) as described [31]. JC-1 is a lipophilic, cationic dye and its advantage is that it can selectively enter into mitochondria based on the aggregation of the probe and reversibly change color from green to red as the membrane potential increases. Cells that had the strongest J-aggregation stained red (560/595nm) due to high MMP and injured cells that stained green (485/535nm) had low MMP. JC-1 stained cells were analyzed using a Live Cell Microscope (Nikon, Melville, New York, USA) (magnification, $\times 10$ ) and expressed as the percentage of green cells in the total cells.

\section{Cytoplasm and membrane protein extraction}

Membrane and cytoplasm separation was performed as described [32] with modification [33]. Briefly, frozen heart tissue was homogenized in lysis buffer A $(20$ mM Tris-Hcl, PH7.5, 2mM EDTA, 2 mM EGTA, 6 $\mathrm{mM} \beta$-mercaptoethanol, $50 \mu \mathrm{g} / \mathrm{ml}$ aprotinin, $48 \mu \mathrm{g} / \mathrm{ml}$ leupetin, $5 \mu \mathrm{M}$ pepstatin, $1 \mathrm{mM}$ PMSF, $0.1 \mathrm{mM} \mathrm{NaVO}_{3}$ and $50 \mathrm{mM} \mathrm{NaF}$ ), with a ultrasonic homogenizers. The obtained homogenate was then centrifuged at 100, $000 \mathrm{~g}$ for 60 minutes, and the supernatant was collected as cytosol fraction. The pellet was suspended in buffer B (buffer A with $0.1 \%$ Triton X-100) and incubated on ice for 30 minutes, vibrated every 10 minutes on the oscillators, then centrifuged at 100, $000 \mathrm{~g}$ for 60 minutes, The resulting supernatant, containing the membrane fraction, was collected.

\section{Western blot analysis}

Frozen ventricular tissue samples were homogenized in lysis buffer (from Cell Signaling Technology (Beverly, MA) and centrifuged at the speed of $13200 \mathrm{~g}$ for 30 minutes. And the proteins from H9C2 cells were also homogenized in lysis buffer and centrifuged at speed of $13200 \mathrm{~g}$ for 15 minutes. The supernatant was collected as total protein and protein concentrations were determined using the Bradford protein assay. Equal amounts of protein from H9C2 cells and rat heart homogenate were resolved by $7.5-12.5 \%$ SDS-PAGE and subsequently transferred to polyvinylidene nitrocellulose membranes and processed as described [15]. Membranes were blocked in TBST containing 5\% (w/v) non-fat milk and dried for 1 hour at room temperature, following by strips incubation with primary antibodies overnight at $4{ }^{\circ} \mathrm{C}$. The primary antibodies against PKC- $\varepsilon$, Akt, STAT3, phosphorylation-Akt (Ser-473), STAT3 at sites of Ser 727 and Tyr 705 and GAPDH were purchased from Cell Signaling Technology (Beverly, MA). Following extensive washing, membrane strips were incubated with secondary antibody 1:5000 anti-rabbit IgG (Cell Signaling Technology, Inc. MA) conjugated to horseradish peroxidase for 1 hour. Protein bands were detected by a standard ECL method and images were measured by a densitometer.

\section{Statistical analysis}

All values are expressed as mean \pm standard error of the mean (S.E.M.). All data are normally distributed as confirmed by Graphpad Prism normality test. Comparisons between multiple groups and treatment for data obtained from in vivo studies were analyzed by two-way ANOVA, while data obtained 


\section{Cellular Physiology \begin{tabular}{l|l} 
and Biochemistry Published online: March 12, 2018 & $\begin{array}{l}\text { (c) } 2018 \text { The Author(s). Published by S. Karger AG, Basel } \\
\text { www.karger.com/cpb }\end{array}$
\end{tabular} \\ Wang et al.: Repeated Non-Invasive Limb Ischemic Preconditioning Confers Protection in Diabetes}

from in vitro studies were analyzed by one-way ANOVA, followed by the Tukey test for multiple comparisons (GraphPad Prism version 7, GraphPad Software, Inc., Lajolla, CA). $P$ values less than 0.05 indicate statistical significance.

\section{Results}

rNLIP conferred cardioprotective effects against myocardial I/RI in diabetes

As shown in Fig. 2A-C, post-ischemic myocardial infarct size (IS) was significantly larger in diabetic than in non-diabetic rats $(P<0.05)$, which was associated with significant increased release of Tn-I (Fig. 2D) and LDH (Fig. 2E) (all $P<0.05$, diabetic $v s$. non-diabetic control, diabetic-I/R vs. non-diabetic-I/R). rNLIP significantly reduced post-ischemic IS and decreased Tn-I and LDH in both non-diabetic and diabetic rats.

rNLIP reduced post-ischemic cardiac $P K C-\varepsilon$ and enhanced STAT3 and Akt in diabetes

After activation, PKC- $\varepsilon$ translocates to the membrane to exert its function [34]. As shown in Fig. 3, cardiac PKC- $\varepsilon$ protein expression as well as its activation, are reflected as an increased ratio of membrane/cytosolic PKC- $\varepsilon$, and were significantly augmented in 8 weeks diabetic rats as compared to non-diabetic controls at basal conditions (Fig. 3A-C). In nondiabetic control rats, I/R induced significant

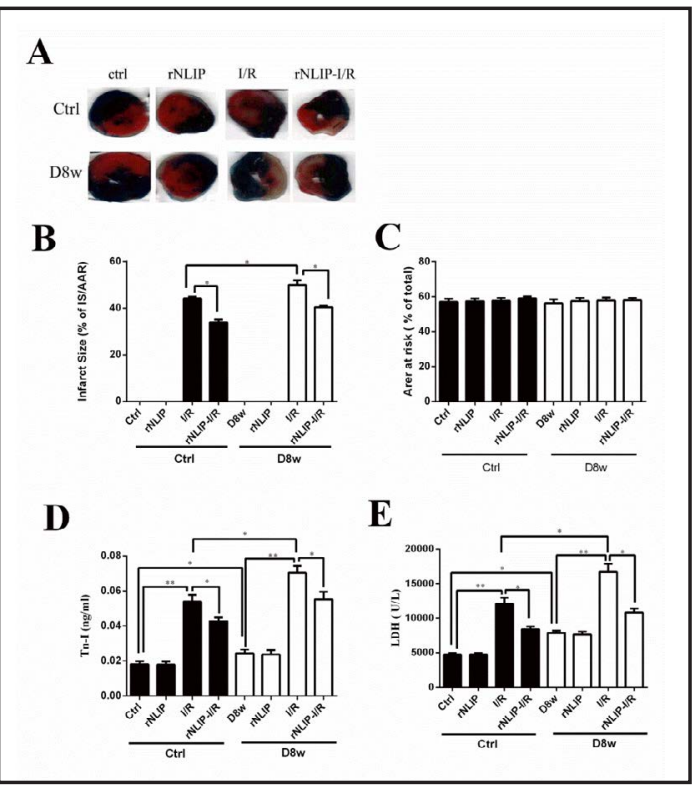

Fig. 2. Effect of rNLIP on post-ischemic myocardial injury in non-diabetic control (Ctrl) and 8 weeks diabetic (D8w) rats. A: Representative images of myocardial necrosis (infarct size) determined by TTC and Evans blue staining; B and C: Post-ischemic infarct size expressed as percentage of infarct size (IS) to the area at risk (AAR); D: Serum troponin-I(TnI) level; E: Serum LDH level. rNLIP was achieved through 3 cycles of 5 minutes ischemia followed by 5 minutes reperfusion in right unilateral hindlimb every day for 3 days, the color of foot during ischemia became purple and was used as an indicator of successful occlusion of blood flow. Ischemia reperfusion $(\mathrm{I} / \mathrm{R})$ was achieved by 30 minutes ischemia and 120 minutes reperfusion. Data are expressed as mean \pm SEM, $\mathrm{n}=6$ per group. ${ }^{*} \mathrm{P}<0.05$. increases in $\mathrm{PKC}-\varepsilon$ protein expression (Fig. 3B) and activation (Fig. 3C) $(P<0.05$, non-diabetic+ I/R $v s$. non-diabetic control), which were further significantly increased by rNLIP $(P<0.05$, non-diabetic+rNLIP+I/R vs. non-diabetic $+\mathrm{I} / \mathrm{R})$. In diabetic rats, I/R caused significant further increases in PKC- $\varepsilon$ expression (Fig. 3B) and activation (Fig. 3C) $(p<0.05$, diabetic+I/R $v s$. diabetic-control) while rNLIP significantly reduced I/R induced increases in both PKC- $\varepsilon$ protein expression and activation $(P<0.05$, diabetic $+r N L I P+I / R v s$. diabetic $+\mathrm{I} / \mathrm{R})$. rNLIP per se did not have a significant impact on cardiac PKC- $\varepsilon$ activation in sham-operated groups both in non-diabetic and diabetic rats (Fig. 3B\&C).

In 8 weeks diabetic rats, both baseline and post-ischemic myocardial phosphorylation of STAT3 (Fig. 3D\&E) and p-Akt(Ser473) (Fig. 3F) were significantly lower than those in the non-diabetic groups and were further significantly reduced by I/R. rNLIP corrected I/R induced reductions of p-STAT3 at both sites of Ser727 (Fig. 3D) and Tyr705 (Fig. 3E) and p-Akt (Ser473) (Fig. 3F) in both non-diabetic and diabetic rats.

Remote time HPC attenuated H/R induced cell injury under high glucose conditions

As shown in Fig. 4A, in cardiac H9C2 cells, H/R induced significant cell injury under both normal (NG) and high glucose (HG) conditions with more severe injury seen in $H G(P<0.05$, 
Wang et al.: Repeated Non-Invasive Limb Ischemic Preconditioning Confers Protection in Diabetes

Fig. 3. Effects of rNLIP on post-ischemic myocardial injury in non-diabetic control (Ctrl) and 8 weeks diabetic (D8w) rats. A : Representative bands of protein PKC- $\varepsilon$-cytosol, PKC- $\varepsilon$-membrane, PKC- $\varepsilon$, p-STAT3(Tyr705), p-STAT3(Ser727), TSTAT3, p-Akt(Ser473) and T-Akt; B: protein expression of PKC- $\varepsilon$; C: Ratio of membrane/ cytosol of PKC- $\varepsilon$ to; D: protein expression of p-STAT3(Ser727); E: protein expression of p-STAT3(Tyr705); F: protein expression of p-Akt(Ser473). rNLIP was achieved through 3 cycles of 5 minutes ischemia followed by 5 minutes reperfusion in unilateral hindlimb every day for 3 days, the color of foot during ischemia became purple and was used as an indicator of successful occlusion of blood flow. I/R was achieved by 30 minutes ischemia and 120 minutes reperfusion. Phosphorylated proteins were assessed by phosphorylation/total protein expression. Data are expressed as mean \pm SEM, $\mathrm{n}=6$ per group. ${ }^{*} \mathrm{P}<0.05$.

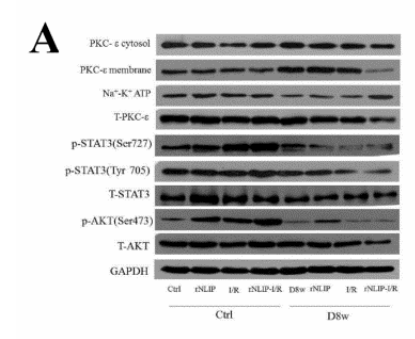

C

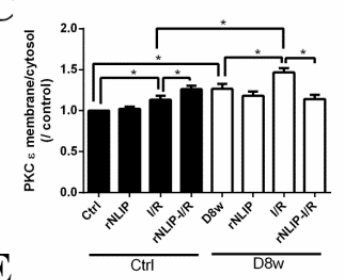

$\mathbf{E}$

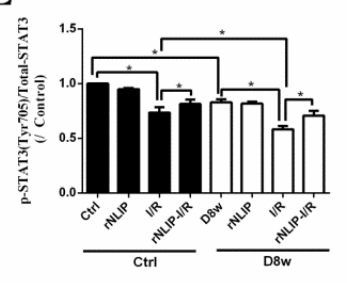

B

D
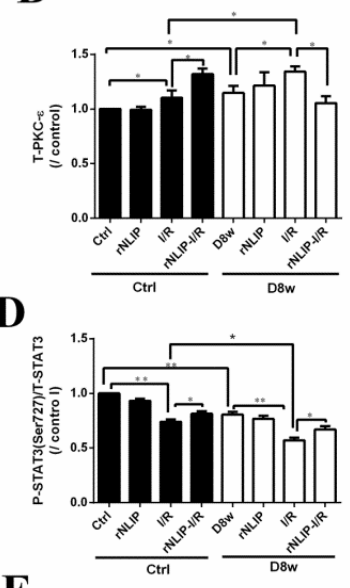

F

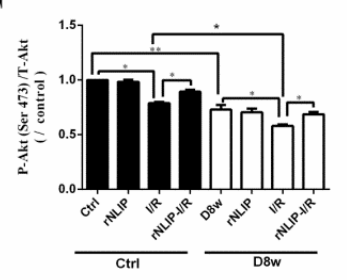

Fig. 4. Effects of remote time HPC on cellular injury in $\mathrm{H} 9 \mathrm{C} 2$ cells exposed to normal glucose (NG) and high glucose (HG) in the presence or absence of hypoxia-reoxygenation (H/R). A: LDH release to culture medium; B: ratio of pro-apoptosis and anti-apoptosis proteins $\mathrm{Bax} / \mathrm{Bcl} 2$; C: MMP assessed by JC-1 staining. In the HG group, $\mathrm{H} 9 \mathrm{C} 2$ cells were subjected $30 \mathrm{mM}$ high glucose for 48 hours before being subjected to 6 hours hypoxia and 12 hours of reperfusion. Remote time HPC was achieved by 3 cycles of 5 minutes hypoxia followed by 5 minutes re-oxygenation 24 hours before $\mathrm{H} / \mathrm{R}$. ${ }^{*} \mathrm{P}<0.05$. Data are expressed as mean \pm SEM of two independent experiments each performed in triplicate. $n=6$ per group.
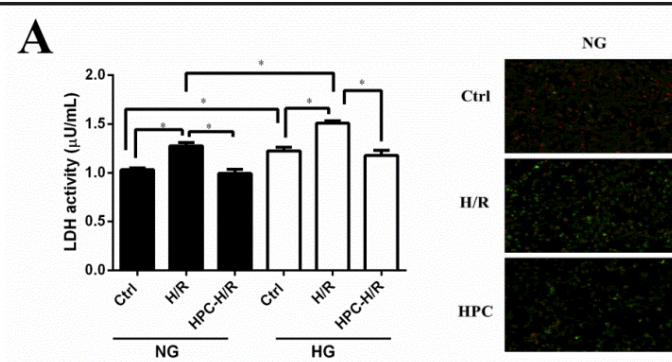

HG

B

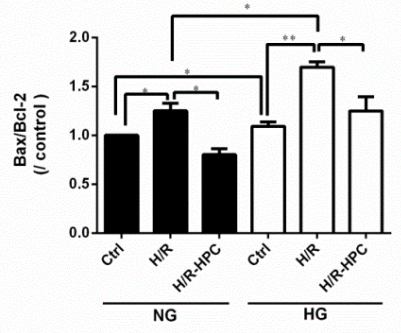

C

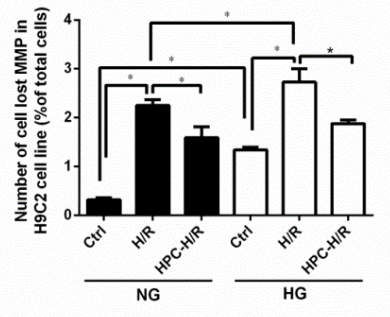

NG-H/R vs. NG-control, $P<0.05, \mathrm{HG}+\mathrm{H} / \mathrm{R} v s . \mathrm{NG}+\mathrm{H} / \mathrm{R})$. This was accompanied by increased ratio of Bax/Bcl-2 protein expression (Fig. 4B) and an increased number of cells that lost mitochondrial membrane potential (MMP, Fig. 4C) manifest as significantly more cells with positive JC-1 staining, which is indicative of increased cell death, in HG conditions relative to that in NG (all $P<0.05$ ). Application of HPC 24 hours prior to inducing H/R (i.e., remote time HPC) significantly attenuated H/R-induced increases in LDH release and Bax/Bcl-2 
expression and reduced the number of cells that lost MMP under both NG and HG conditions (Fig. 4A-C). The osmotic control, mannitol, had no significant effects on protein expression such as $\mathrm{Bax} / \mathrm{Bcl}-2$ and did not affect LDH release (data not shown).

\section{Effects of remote time $H P C$ on $P K C-\varepsilon$ activation in $\mathrm{H} 9 \mathrm{C} 2$ cells subjected to $H / R$}

As shown in Fig. 5, expression of both total (Fig. 5A) and the ratio of membrane/cytosol (Fig. 5B) PKC- $\varepsilon$ were increased in $\mathrm{H} 9 \mathrm{C} 2$ cells exposed to $\mathrm{HG}$ as compared to NG $(P<0.05) . H / R$ significantly increased the expression of total (Fig. 5A) and the ratio of membrane/cytosol (Fig.

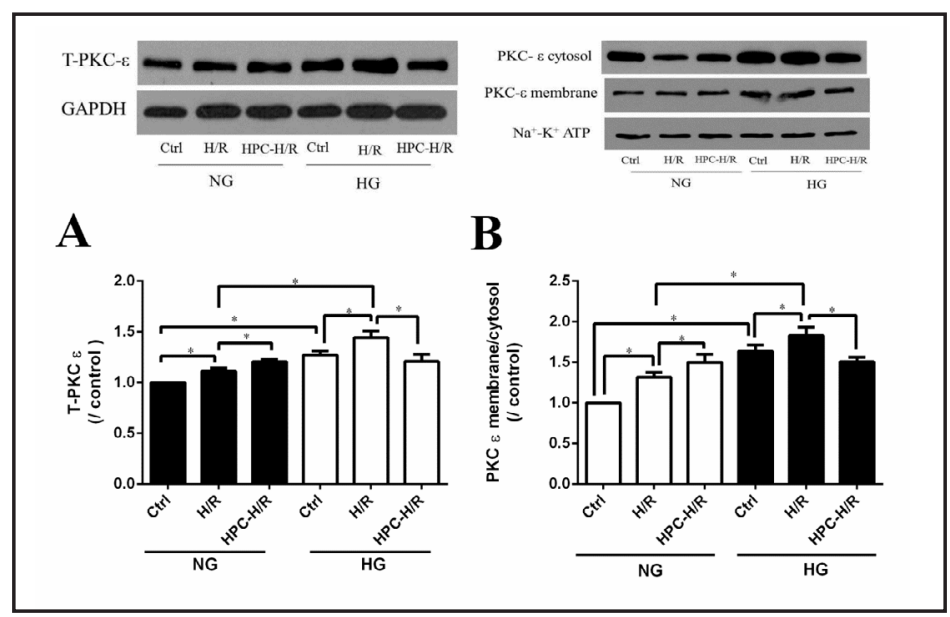

Fig. 5. Effects of remote time HPC on activity of PKC- $\varepsilon$ in H9C2 cells

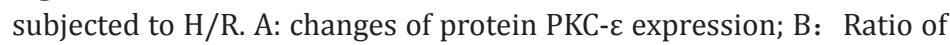
membrane/cytosol of PKC- $\varepsilon$ in H9C2 cells exposed to normal glucose (NG, $5.5 \mathrm{mM}$ ) or high glucose ( $\mathrm{HG}, 30 \mathrm{mM}$ ) and subjected to 6 hours hypoxia and 12 hours re-oxygenation with or without remote time HPC. Remote time HPC was achieved by 3 cycles of 5 minutes hypoxia followed by 5 minutes re-oxygenation 24 hours before $H / R$. ${ }^{*} \mathrm{P}<0.05$. Data are expressed as mean \pm SEM of two independent experiments each performed in triplicate. $n=6$ per group.

5B) PKC- $\varepsilon$ under both NG and HG conditions ( $p<0.05$, NG-H/R vs.NG-control, HG-H/R vs. HGcontrol). Remote time HPC significantly further increased post-hypoxic total and membrane/ cytosol PKC- $\varepsilon$ under NG condition but reduced both post-hypoxic total and membrane/cytosol PKC- $\varepsilon$ under HG conditions. Given that translocating from cytosol to membrane represents activation of PKC- $\varepsilon$, these results indicate that remote time HPC reduces post-hypoxic PKC- $\varepsilon$ activation to confer cardiac protection under HG conditions. The osmotic control, mannitol, exerted no effects on PKC- $\varepsilon$ expression. We also did the experiments to verify the effects of HPC alone on PKC translocation and found that HPC alone had no significant effect on PKC- $\varepsilon$ translocation (data not shown).

Effects of remote time HPC on the protein expression of STAT3 and Akt in H9C2 cells subjected to $H / R$

Akt and STAT3 are the major pro-survival proteins in the RISK and SAFE signaling pathways related to IPC. As shown in Fig. 6A-D, the expression levels of proteins p-STAT3-Ser727 (Fig. 6B) and p-STAT3-Tyr 705 (Fig. 6C) were significantly lower in the HG than the NG group under both baseline and H/R conditions (all $p<0.05$ ). HPC significantly attenuated H/R-induced reductions of p-STAT3 both under NG and HG conditions (all $p<0.05$ ). H/R significantly reduced the expression of p-Akt(Ser473) under HG conditions $(p<0.05$, $\mathrm{HG}+\mathrm{H} / \mathrm{R} v s$. HG-control, Fig. 6D) but not during NG ( $P>0.05$, Fig. 6D). HPC significantly increased the expression of p-Akt(Ser473) during $N G$ and reverted $H / R$ induced reduction of p-Akt(Ser473) under HG conditions $(p<0.05, \mathrm{NG}+\mathrm{H} / \mathrm{R}+\mathrm{HPC} v s . \mathrm{NG}+\mathrm{H} / \mathrm{R}, \mathrm{HG}+\mathrm{H} / \mathrm{R}+\mathrm{HPC} v s$. $\mathrm{HG}+\mathrm{H} / \mathrm{R}$, Fig. 6D).

STAT3 gene knock-down cancelled the protective effects of remote time HPC in cardiac H9C2 cells

In an animal study we found that rNLIP conferred cardioprotection by activating PKC-ع, while in diabetes rNLIP moderately but significantly reduced the expression and activation of PKC- $\varepsilon$ and increased the activation of STAT3 to confer cardioprotection. While the roles 
Wang et al.: Repeated Non-Invasive Limb Ischemic Preconditioning Confers Protection in Diabetes

Fig. 6. Remote time HPC activated protein STAT3 and Akt expressions in $\mathrm{H} 9 \mathrm{C} 2$ cells subjected to hypoxic reoxygenation $(\mathrm{H} / \mathrm{R})$. A: Representative bands of protein $\mathrm{p}$ STAT3(Tyr705), p-STAT3(Ser727), T-STAT3, p-Akt(Ser473), T-Akt; $\mathrm{B}$ : protein expression of $\mathrm{p}$ STAT3(Ser727); C: protein expression of p-STAT3(Tyr705); D: protein expression of p-Akt(Ser473) in cells exposed to normal glucose and high glucose in the presence or absence of HPC. In HG group, H9C2 cells were subjected $30 \mathrm{mM}$ high glucose for 48 hours, and then all cells subjected to 6 hours hypoxia and 12 hours reperfusion. Remote time HPC was achieved by 3 cycles of 5 minutes hypoxia followed by 5 minutes re-oxygenation 24 hours before H/R. Phosphorylated pro-

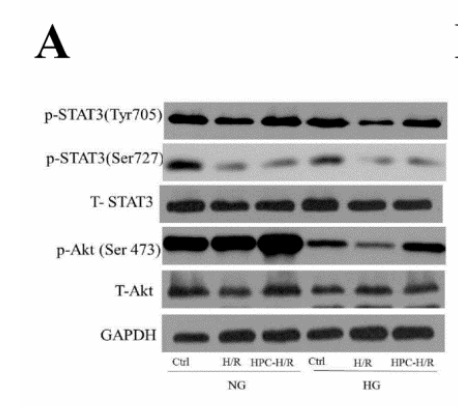

B

C

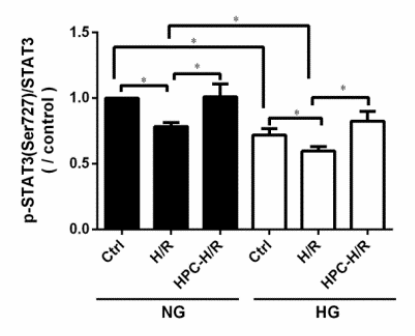

D
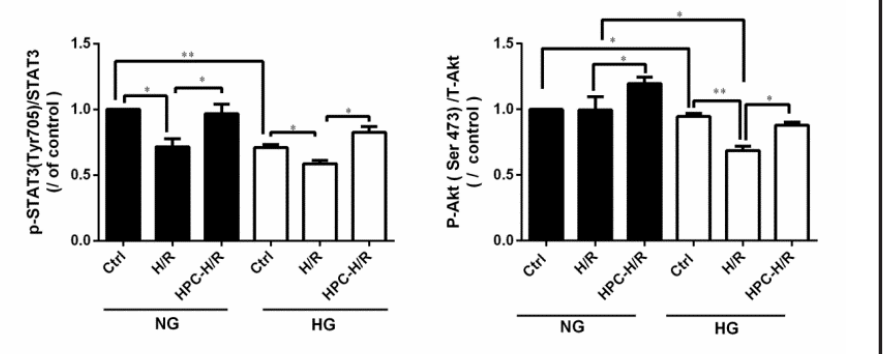
teins were assessed by phosphorylation/total protein expression. ${ }^{*} \mathrm{P}<0.05$. Data are expressed as mean $\pm \mathrm{SEM}$ of two independent experiments each performed in triplicate. $n=6$ per group.

of STAT3 and PKC- $\varepsilon$ in the relationship between STAT3 and PKC- $\varepsilon$ in rNLIP in diabetic or hyperglycemic conditions have yet to be explored. To further confirm the role of STAT3 activation in remote time HPC cellular protection during HG, siRNA was used to knock down STAT3 in cells treated with or without remote time HPC. As shown in Fig. 7A and 7B, STAT3 gene knock-down decreased the expression of STAT3 significantly compared to control $(P<0.01)$. Control siRNA did not significantly affect the protein expression of STAT3 (data not shown). Further, STAT3 gene knock-down canceled remote time HPC mediated cellular protection manifest as elevated LDH release $(P<0.05, \mathrm{HG}+\mathrm{H} / \mathrm{R}+\mathrm{HPC}+\mathrm{siRNA}$ STAT3 vs. $\mathrm{HG}+\mathrm{H} / \mathrm{R}+\mathrm{HPC} ; \mathrm{P}>0.05, \mathrm{HG}+\mathrm{H} / \mathrm{R}+\mathrm{HPC}+$ siRNA STAT3 vs. HG+H/R, Fig. 7D). As shown in Fig. 7E, STAT3 gene knock-down had no effect on PKC- $\varepsilon$ protein expression under $H / R$, and remote time HPC significantly attenuated the H/R-induced increase of post-hypoxic PKC- $\varepsilon$ expression under $\mathrm{HG}$ conditions ( $p<0.05, \mathrm{HG}+\mathrm{HPC}+\mathrm{H} / \mathrm{R}$ group $v s . \mathrm{HG}+\mathrm{H} / \mathrm{R}$ group) both in the absence or presence of siRNA STAT3. This suggests that PKC- $\varepsilon$ works upstream of STAT3 in this experimental setting. HG exposure significantly reduced STAT3 activation manifested as reduced phosphorylation at both sites Tyr705 $(p<0.05$, HG-control vs. NG-control, Fig. 7F) and Ser727 ( $p<0.05$, HG-control vs. NG-control, Fig. 7G), which were further significantly reduced by $\mathrm{H} / \mathrm{R}(p<0.05, \mathrm{HG}+\mathrm{H} / \mathrm{R} v s$. HG-control, Fig. $7 \mathrm{~F} \& \mathrm{G})$. These changes were reverted by HPC $(p<0.05, \mathrm{HG}+\mathrm{H} / \mathrm{R}+\mathrm{HPC} v s$. HG+H/R, Fig. 7 F\&G). Further, STAT3 gene knock-down prevented remote time HPC to revert H/R induced reductions in p-STAT3 at both Tyr705 and Ser727 ( $P>0.05, \mathrm{HG}+\mathrm{H} / \mathrm{R}+\mathrm{HPC}+$ siRNA STAT3 vs. HG+H/R+HPC, Fig. 7 F\&G). As shown in Fig. 7H, p-Akt(Ser473) was significantly decreased after H/R, and HPC increased the expression of p-Akt(Ser473) (all $p<0.05, \mathrm{HG}+\mathrm{H} / \mathrm{R} v s$. HG-control, HG+H/R+HPC vs. HG+H/R, Fig. 7H), while STAT3 gene knock-down canceled remote time HPC-induced increase of p-Akt(Ser473) (Fig. 7H). 


\section{Cellular Physiology \begin{tabular}{ll|l} 
and Biochemistry Published online: March 12, 2018 & $\begin{array}{l}\text { C) } 2018 \text { The Author(s). Published by S. Karger AG, Basel } \\
\text { www.karger.com/cpb }\end{array}$ \\
\hline
\end{tabular} \\ Wang et al.: Repeated Non-Invasive Limb Ischemic Preconditioning Confers Protection in Diabetes}

Fig. 7. Effects of STAT3 gene knockdown on remote time HPC cellular protection in $\mathrm{H} 9 \mathrm{C} 2$ cells. A: Representative band of protein T-STAT3 expression; B: changes of expression of STAT3 after gene knock down STAT3; C: Representative bands of protein of PKC- $\varepsilon$, p-STAT3(Tyr705), pSTAT3(Ser727), T-STAT3, p-Akt(Ser473), T-Akt ; D: LDH release to culture medium; E: protein expression of PKC- $\varepsilon$; F: protein expression of p-STAT3(Tyr705); G: protein expression of p-STAT3(Ser727); H: protein expression of p-Akt(Ser473) in cells with STAT3 gene knockdown (siRNA STAT3) in the presence or absence of remote time HPC. In HG group, H9C2 cells were subjected to $30 \mathrm{mM}$ high glucose for 48 hours, and then all cells subjected to 6 hours hypoxia and 12 hours reperfusion. Remote time HPC was achieved by 3 cycles of 5 minutes hypoxia followed by 5 minutes re-oxygenation 24 hours before H/R. Phosphorylated proteins were assessed by phosphorylation/total protein expression. ${ }^{*} \mathrm{P}<0.05$. Data are expressed as mean \pm SEM of two independent experiments each performed in triplicate. $n=6$ per group.
A

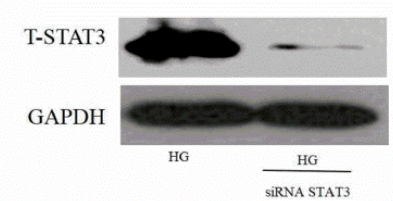

B

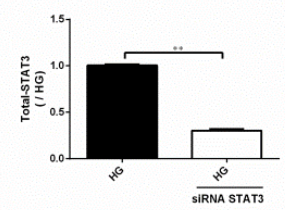

$\mathbf{E}$

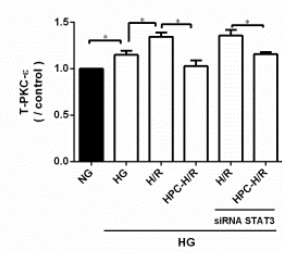

G

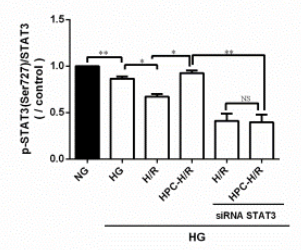

C

D

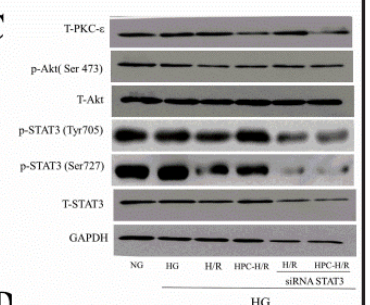

HG

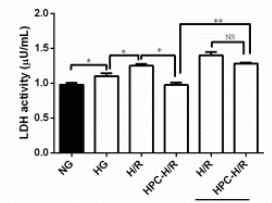

F

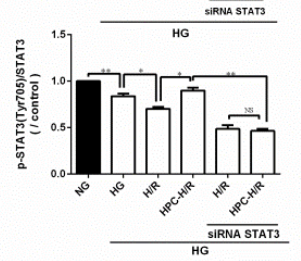

H

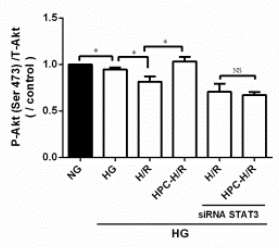

\section{Effects of PKC-E gene knock-down on post-hypoxic p-STAT3 and p-Akt during remote time}

$H P C$

To verify the role of PKC- $\varepsilon$ in remote time HPC mediated cardiac protection and its impact on pro-survival signaling under HG conditions, PKC- $\varepsilon$ siRNA was used to knock down PKC- $\varepsilon$. As shown in Figs. 8A and8B, PKC- $\varepsilon$ gene knock-down decreased the expression of PKC- $\varepsilon$ significantly compared to control $(P<0.05)$. Control siRNA did not significantly affect the protein expression of PKC- $\varepsilon$ (data not shown). Under HG, post-hypoxic LDH release (Fig. $8 \mathrm{D})$ was significantly increased in cells subjected to $\mathrm{H} / \mathrm{R}$ which was significantly reduced by HPC and also by PKC- $\varepsilon$ gene knock-down separately (all $p<0.05, \mathrm{HG}+\mathrm{H} / \mathrm{R} v s$. HG-control, $\mathrm{HG}+\mathrm{H} / \mathrm{R}+\mathrm{HPC} v s . \mathrm{HG}+\mathrm{H} / \mathrm{R}, \mathrm{HG}+\mathrm{H} / \mathrm{R}+$ siRNA PKC $-\varepsilon v s$. HG+H/R), while HPC plus PKC $-\varepsilon$ gene knock-down did not have significantly added effects in reducing post-hypoxic LDH release, indicating that HPC conferred cellular protection primarily via reducing H/R induced increases in PKC- $\varepsilon$ under HG conditions. The expression of PKC- $\varepsilon$ was significantly increased during HG exposure and further increased after $\mathrm{H} / \mathrm{R}$, with $\mathrm{HPC}$ significantly reducing the $\mathrm{HG}+\mathrm{H} / \mathrm{R}$-induced increase in PKC- $\varepsilon$ expression $(P<0.05, \mathrm{HG}+\mathrm{H} / \mathrm{R}+\mathrm{HPC} v s . \mathrm{HG}+\mathrm{H} / \mathrm{R}, \mathrm{Fig} .8 \mathrm{E})$. $\mathrm{PKC}-\varepsilon$ gene knock-down resulted in a profound decrease of post-hypoxic PKC- $\varepsilon$ expression in both the $\mathrm{H} / \mathrm{R}$ and $\mathrm{HPC}+\mathrm{H} / \mathrm{R}$ groups $(P<0.05, \mathrm{HG}+\mathrm{H} / \mathrm{R}+$ siRNA PKC- $\varepsilon v s . \mathrm{HG}+\mathrm{H} / \mathrm{R}, \mathrm{HG}+\mathrm{H} /$ $\mathrm{R}+\mathrm{HPC}+$ siRNA PKC $-\varepsilon v s$. HG+H/R+HPC, Fig. 8E), while HPC did not have significant impact on post-hypoxic $\mathrm{PKC}-\varepsilon$ expression in the presence of $\mathrm{PKC}-\varepsilon$ gene knock-down.

Compared to control, phosphorylation/activation of STAT3 at sites Tyr705 (Fig. 8F) and Ser727 (Fig. 8G) decreased significantly under HG conditions and further significantly reduced after $\mathrm{H} / \mathrm{R}$, while remote time $\mathrm{HPC}$ reverted $\mathrm{H} / \mathrm{R}$ induced reduction of STAT3 activation at both sites Tyr 705 (Fig. 8F) and Ser727 (Fig. 8G). PKC- $\varepsilon$ gene knock-down did not have a significant impact on either $\mathrm{HG}+\mathrm{H} / \mathrm{R}$ induced reduction nor $\mathrm{HG}+\mathrm{H} / \mathrm{R}+\mathrm{HPC}$ induced elevation in p-STAT3(Tyr 705) (Fig. 8F), but resulted in a significant increase in p-STAT3(Ser727) 
Fig. 8. Protein expressions changes and LDH release in $\mathrm{H} 9 \mathrm{C} 2$ cells after gene knockdown $\mathrm{PKC}-\varepsilon$ subjected to $\mathrm{H} / \mathrm{R}$ with or without remote time HPC. A: Representative band of protein PKC- $\varepsilon$ expression; B: effect of siRNA on $\mathrm{PKC}-\varepsilon$ protein expression; C: protein expression of PKC- $\varepsilon$, p-STAT3(Tyr705), pSTAT3(Ser727), T-STAT3, p-Akt(Ser473), T-Akt; D: LDH release to culture medium; E: protein expression of PKC- $\varepsilon$ : protein expression of p-STAT3(Tyr 705); G: protein expression of p-STAT3(Ser727); H: protein expression of p-Akt(Ser473) in H9C2 cells exposed to HG for 48 hours and subjected to 6 hours hypoxia followed by 12 hours re-oxygenation in the presence or absence of remote time HPC and/or PKC- $\varepsilon$ gene knockdown. Remote time HPC was achieved by 3 cycles of 5 minutes hypoxia followed by 5 minutes re-oxygenation 24 hours before H/R. Phosphorylated proteins were assessed by phosphorylation/total protein expression. ${ }^{*} \mathrm{P}<0.05$. Data are expressed as mean \pm SEM of two independent experiments each performed in triplicate. $n=6$ per group.

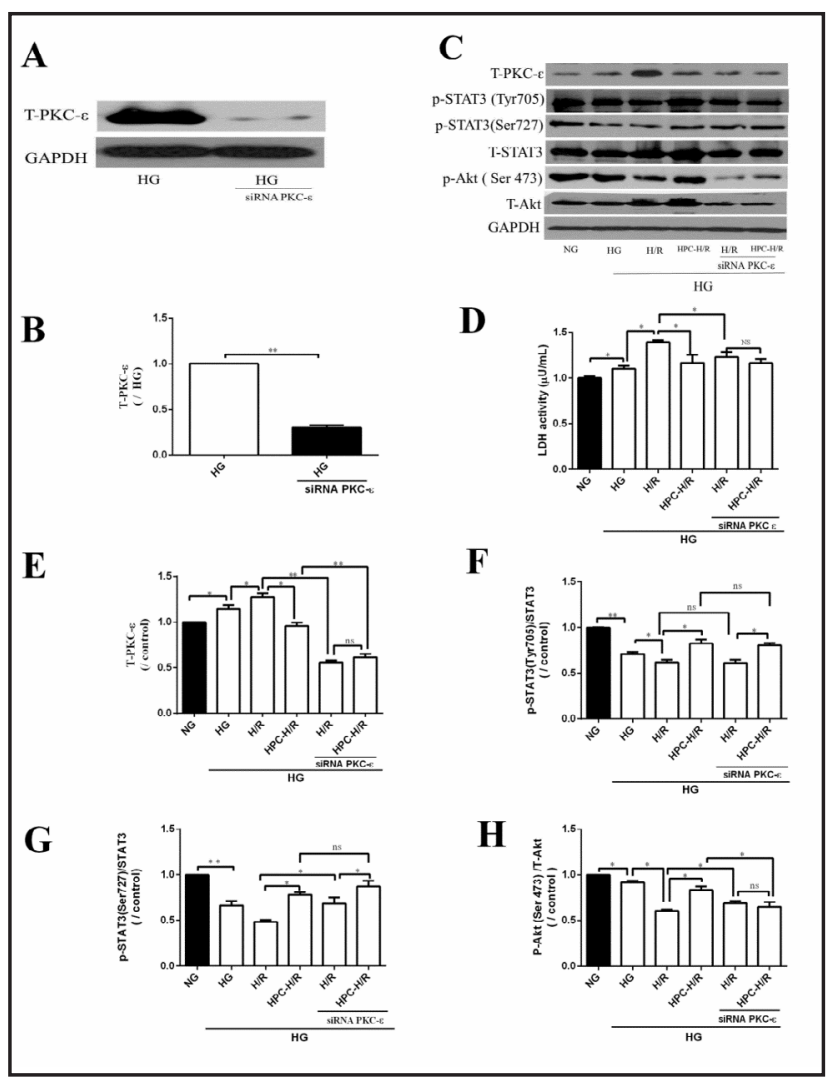

expression in cells subjected to HG+H/R $(P<0.05, \mathrm{HG}+\mathrm{H} / \mathrm{R}+\mathrm{siRNA} \mathrm{PKC}-\varepsilon v s$. HG+H/R, Fig. 8G), while PKC- $\varepsilon$ gene knock-down did not further significantly enhance $\mathrm{HG}+\mathrm{H} / \mathrm{R}+\mathrm{HPC}$ induced increases in p-STAT3(Ser727) expression ( $p>0.05, \mathrm{HG}+\mathrm{H} / \mathrm{R}+\mathrm{HPC}+\operatorname{siRNA} \mathrm{PKC}-\varepsilon$ vs. HG+H/ R+HPC, Fig. 8G). As shown in Fig. 8H, HG resulted in a moderate but statistically significant reduction in p-Akt (Ser473). p-Akt(Ser473) was further significantly reduced after H/R, while HPC reverted H/R induced reduction of p-Akt(Ser473) $(p<0.05, \mathrm{HG}+\mathrm{HPC}+\mathrm{H} / \mathrm{R} v s$. $\mathrm{HG}+\mathrm{H} / \mathrm{R})$. PKC- $\varepsilon$ gene knock-down increased post-hypoxic p-Akt $(p<0.05, \mathrm{HG}+\mathrm{H} / \mathrm{R}+$ siRNA PKC- $\varepsilon v s$. HG+H/R, Fig. 8H). However, PKC- $\varepsilon$ gene knock-down significantly compromised and prevented the HPC-mediated increase in post-hypoxic p-Akt(Ser473) $(p<0.05, \mathrm{HG}+\mathrm{H} /$ $\mathrm{R}+\mathrm{HPC}+\mathrm{siRNA} \mathrm{PKC}-\varepsilon v s . \mathrm{HG}+\mathrm{H} / \mathrm{R}+\mathrm{HPC})$.

\section{Discussion}

We found that rNLIP reduced myocardial I/RI in both non-diabetic and diabetic rats. In non-diabetic hearts rNLIP conferred cardioprotection by enhancing PKC- $\varepsilon$ activation, while in diabetes, cardiac PKC- $\varepsilon$ was over activated which concurs with a previous study [35]. rNLIP conferred cardioprotection by reducing PKC- $\varepsilon$ activation which is the opposite of what is seen in non-diabetic conditions. These results were confirmed by inducing H/R and applying remote time HPC in cardiomyocyte H9C2 cells without or with PKC- $\varepsilon$ gene knockdown and high glucose (HG) exposure. This showed that HG exposure significantly increased PKC- $\varepsilon$ activation and exacerbated H/R-induced cellular injury, and all these changes were reverted by remote time HPC.

Our finding that rNLIP conferred cardioprotection by activating PKC- $\varepsilon$ in non-diabetic but by reverting the over-activation of PKC- $\varepsilon$ in diabetic rats, indicates that the role of PKC- $\varepsilon$ in rNLIP may vary under different conditions. Indeed, previous research has shown that IPC needs to activate PKC- $\varepsilon$ to confer cardioprotection and that application of the PKC- $\varepsilon$ inhibitor 
Wang et al.: Repeated Non-Invasive Limb Ischemic Preconditioning Confers Protection in Diabetes

عv1-2 abolishes the cardioprotection of IPC in non-diabetic conditions. However, given the diversity of models and protocols and the relative but not absolute selectivity of currently available PKC inhibitors, it is difficult to set a standard for PKC- $\varepsilon$ inhibition to determine the role of PKC- $\varepsilon$. Further studies are needed to incorporate the use of cardiac specific PKC$\varepsilon$ knockout or overexpression in control and diabetic rodents to define the role of PKC- $\varepsilon$ in myocardial I/RI $[34,36]$. One possible explanation for the difference of PKC- $\varepsilon$ activation during rNLIP between non-diabetic and diabetic conditions could be that PKC- $\varepsilon$, when activated at a moderate level, stimulates a small amount of reactive oxygen species (ROS) [37], which serves as a trigger of IPC/NLIP [38] which then stimulates downstream targets to confer cardioprotection. Over-activation of PKC- $\varepsilon$ under diabetic conditions in our current study, may have resulted in overproduction of ROS [37] which exacerbated myocardial I/R injury and diminished IPC or NLIP cardioprotection in diabetic hearts. Further research would be useful to test this intriguing hypothesis.

Studies have shown that STAT3 is not only important for cardiomyocyte function, but also modulates the cardiac microenvironment and communicates with cardiac fibroblasts. STAT3 plays major roles in I/RI [39-42], preconditioning and postconditioning cardioprotection and PKC- $\varepsilon$ is essential for conditioning stimuli to activate STAT3 in non-diabetic conditions. However, the role of STAT3 in relation to PKC- $\varepsilon$ in rNLIP mediated cardioprotection in diabetes has not been explored. STAT3 activation in the mitochondria is critical for cardioprotection in reducing post-ischemic infarct size [41-43], and specific inhibition of STAT3 with Stattic enhanced ROS formation and subsequently resulted in problems with mitochondrial function [42], despite the fact that ROS may have dual effects during myocardial I/RI in maintaining STAT3 activity [42]. Our finding that remote time HPC mediated up-regulation of PKC- $\varepsilon$ and the subsequent activation of STAT3 at site Ser727 and cardiac protection against H/R injury under NG conditions were abolished by STAT3 gene knock-down, suggests that STAT3 worked as the main downstream target of PKC- $\varepsilon$ during rNLIP. Our findings and those of others which show that PKC- $\varepsilon$ is essential for IPC to activate STAT3 at site Ser727 to confer its late phase cardioprotection $[17,20]$ and that PKC- $\varepsilon$ activation induced STAT3 phosphorylation, while PKC- $\varepsilon$ knockdown reduced STAT3 [21], indicate the importance of PKC- $\varepsilon$ in STAT3 activation. Our results show that the relationship between PKC- $\varepsilon$ and STAT3 activation in myocardial I/R and IPC or rNLIP may vary depending on the environment e.g. non-diabetic or diabetic. In the study of Kim et al. [44], no direct interaction was found between PKC and STAT3 during IPC in astrocytes, suggesting that PKC- $\varepsilon$ and STAT3 interaction may also be organ or tissue specific [45].

It is interesting to note that STAT3 is not only important for the cardioprotection mediated by ischemic and remote ischemic preconditioning $[14,46]$ but is also critical in postconditioning cardioprotection $[47,48]$. Reduced levels of STAT3 protein in the aged hearts of rodents may be responsible for the loss of cardioprotection by preconditioning and postconditioning [47]. However, during remote ischemic preconditioning, STAT3 was not the only protein activated by RIPC and its activation by RIPC could be species and/or protocol specific. For example, in humans, RIPC has been shown to increase the phosphorylation of STAT5, and in rats and pigs, RIPC has been shown to increase the phosphorylation of STAT3 [14]. However, a recent study of ours in patients showed that RIPC, when applied about one hour before open heart surgery can significantly increase the cardiac phosphorylation/activation of both STAT3 and STAT5 and reduce the myocardial I/RI in children with tetralogy of Fallot [49]. It has also been shown that STAT3 played a central role in the development of postpartum cardiomyopathy [50]. A recent study examining the dynamic changes of cardiac STAT3 after myocardial I/RI and the effects of ischemic postconditioning, showed that cardiac p-STAT3 increased as early as 5 minutes after reperfusion following ischemic postconditioning and p-STAT3 decreased thereafter, while the ischemic postconditioning-initiated cardioprotection remained [51], suggesting a long term cardioprotective effect of STAT3 activation.

A limitation is that we only performed studies in type 1 diabetes which may differ from type 2 in terms of the mechanism of onset and prevalence. However, at the end of long term diabetes, both type 1 and type 2 share common characteristics such as impaired insulin 


\section{Cellular Physiology Cell Physiol Biochem 2018;45:2107-2121 \\ \begin{tabular}{ll|l} 
DOI: 10.1159/000488047 & $\begin{array}{l}\text { O 2018 The Author(s). Published by S. Karger AG, Basel } \\
\text { www.karger.com/cpb }\end{array}$ \\
\cline { 2 - 3 }
\end{tabular} \\ Wang et al.: Repeated Non-Invasive Limb Ischemic Preconditioning Confers Protection \\ in Diabetes}

signaling and hyperglycemia. Therefore, insight gained from our current study may elucidate the potential interventions that could attenuate diabetic myocardial ischemia-reperfusion injury in general, although future studies in type 2 diabetic rodents and in humans are still warranted. Another limitation is that in the cell studies the "remote time" HPC protocol cannot replicate all aspects of remote IPC. The effects of what the culture media can do to naïve cells after they have undergone the HPC protocol could not be determined and this deserves further study. Also, the role of PKC- $\varepsilon$ in high glucose induced cell injury in the absence of hypoxia/reoxygenation should be explored.

\section{Conclusion}

Overexpression and activation of cardiac PKC- $\varepsilon$ may represent a major mechanism that renders diabetics unresponsive to conventional IPC or NLIP cardioprotection, and that rNLIP attenuates diabetic heart I/R injury by mitigating HG-induced PKC- $\varepsilon$ overexpression and by subsequently activating cardiac STAT3 at site Tyr 727.

Patients with diabetes are more vulnerable to myocardial I/R injury. Repeated noninvasive limb ischemic preconditioning (rNLIP) protects the heart against myocardial I/ $\mathrm{RI}$ in rats with diabetes but the underlying mechanism is unclear. The present study was designed to investigate the role of PKC- $\varepsilon$ in diabetic myocardial I/R injury and in rNLIP cardioprotection. Our results show that, in non-diabetic hearts, rNLIP, by activating PKC- $\varepsilon$, activates STAT3 and Akt to confer its cardioprotection. In diabetic hearts, in which PKC- $\varepsilon$ is over-activated, rNLIP, by down-regulating PKC- $\varepsilon$, restores STAT3 to confer cardioprotection. It is strongly suggestive that targeting inhibition of PKC- $\varepsilon$ may be a potential clinical therapeutic intervention in the treatment of diabetes-associated cardiac disease

\section{Acknowledgements}

The authors acknowledge Dr. Zipeng Liu for technical assistance during the experiments, and acknowledge Shenzhen Ivy-Valued Biotechnology Co. Ltd. for editing service.

This research was supported by General Research Fund (768211M and $17121315 \mathrm{M}$ to MGI, and 17158616M to ZX) from Research Grants Council of Hong Kong and The University of Hong Kong Seeding grant for Basic Science.

Conceived and designed the experiments: ZX, MGI, and CW. Performed the experiments: CW, ZX, HL, XM, and SW. Analyzed the data: CW, ZX, and MGI. Contributed reagents/materials/ analysis tools: SSW. Wrote the paper: CW, HL, ZX, and MGI.

\section{Disclosure Statement}

No conflicts of interest are declared by the authors.

\section{References}

1 Whittington H J, Babu G.G, Mocanu MM, Yellon DM, Hausenloy D: The diabetic heart: too sweet for its own good? Cardiol Res Pract 2012;2012:845698.

-2 Yellon DM, Hausenloy DJ: Myocardial reperfusion injury. N Engl J Med 2007;357:1121-1135.

-3 van der Does L, Kik C, Allessie M, de Groot N: Endo-epicardial dissociation in conduction. Eur Heart J 2017;38:1775.

4 Ibanez B, Heusch G, Ovize M, Van de Werf F: Evolving therapies for myocardial ischemia/reperfusion injury. J Am Coll Cardiol 2015;65:1454-1471. 


\section{Cellular Physiology Cell Physiol Biochem 2018;45:2107-2121 \begin{tabular}{l|l|l}
\hline DOI: 10.1159/000488047 & $\begin{array}{l}\text { () 2018 The Author(s). Published by S. Karger AG, Basel } \\
\text { www.karger.com/cpb }\end{array}$ \\
\hline
\end{tabular}}

Wang et al.: Repeated Non-Invasive Limb Ischemic Preconditioning Confers Protection in Diabetes

5 Murry CE, Jennings RB, Reimer KA: Preconditioning with ischemia: a delay of lethal cell injury inischemic myocardium. Circulation 1986;74:1124-1136.

6 Jing N, Fang B, Wang ZL, Ma H: Remote Ischemia Preconditioning Attenuates Blood-Spinal Cord Barrier Breakdown in Rats Undergoing Spinal Cord Ischemia Reperfusion Injury: Associated with Activation and Upregulation of CB1 and CB2 Receptors. Cell Physiol Biochem 2017;43:2516-2524.

7 Zhang J, Zhang J, Yu P, Chen M, Peng Q, Wang Z, Dong N: Remote Ischaemic Preconditioning and Sevoflurane Postconditioning Synergistically Protect Rats from Myocardial Injury Induced by Ischemia and Reperfusion Partly via Inhibition TLR4/MyD88/NF-kappaB Signaling Pathway. Cell Physiol Biochem 2017;41:22-32.

8 Hausenloy DJ, Barrabes JA, Botker HE, Davidson SM, Di Lisa F, Downey J, Engstrom T, Ferdinandy P, Carbrera-Fuentes HA, Heusch G, Ibanez B, Iliodromitis EK, Inserte J, Jennings R, Kalia N, Kharbanda R, Lecour S, Marber M, Miura T, Ovize M, Perez-Pinzon MA, Piper HM, Przyklenk K, Schmidt MR, Redington A, Ruiz-Meana M, Vilahur G, Vinten-Johansen J, Yellon DM, Garcia-Dorado D: Ischaemic conditioning and targeting reperfusion injury: a 30 year voyage of discovery. Basic Res Cardiol 2016;111:70.

-9 Heusch G, Botker HE, Przyklenk K, Redington A, Yellon D: Remote ischemic conditioning. J Am Coll Cardiol 2015;65:177-195.

10 Kleinbongard P, Skyschally A, Heusch G: Cardioprotection by remote ischemic conditioning and its signal transduction. Pflugers Arch 2017;469:159-181.

11 Zhu XH, Yuan HJ, Wu YN, Kang Y, Jiao JJ, Gao WZ, Liu YX, Lou JS, Xia Z: Non-invasive limb ischemic preconditioning reduces oxidative stress and attenuates myocardium ischemia-reperfusion injury in diabetic rats. Free Radic Res 2011;45:201-210.

12 Gao J, Kang Y, Lou, JS: The optimal strategy of noninvasive limb ischemic preconditioning for protecting heart against ischemia-reperfusion injury in rats. J Surg Res 2012;174:e47-54.

-13 Das A, Salloum FN, Filippone SM, Durrant DE, Rokosh G, Bolli R, Kukreja RC: Inhibition of mammalian target of rapamycin protects against reperfusion injury in diabetic heart through STAT3 signaling. Basic Res Cardiol 2015;110:31.

14 Skyschally A, Gent S, Amanakis G, Schulte C, Kleinbongard P, Heusch G: Across-Species Transfer of Protection by Remote Ischemic Preconditioning With Species-Specific Myocardial Signal Transduction by Reperfusion Injury Salvage Kinase and Survival Activating Factor Enhancement Pathways. Circ Res 2015;117:279-288.

15 Wang T, Mao X, Li H, Qiao S, Xu A, Wang J, Lei S, Liu Z, Ng KF, Wong GT, Vanhoutte PM, Irwin MG, Xia Z: $\mathrm{N}$-Acetylcysteine and allopurinol up-regulated the Jak/STAT3 and PI3K/Akt pathways via adiponectin and attenuated myocardial postischemic injury in diabetes. Free Radic Biol Med 2013;63:291-303.

16 Han Z, Cao J, Song D, Tian L, Chen K, Wang Y, Gao L, Yin Z, Fan Y, Wang C: Autophagy is involved in the cardioprotection effect of remote limb ischemic postconditioning on myocardial ischemia/reperfusion injury in normal mice, but not diabetic mice. PLoS One 2014;9:e86838.

17 Xuan YT, Guo Y, Zhu Y, Wang OL, Rokosh G, Messing RO, Bolli R: Role of the protein kinase C-epsilonRaf-1-MEK-1/2-p44/42 MAPK signaling cascade in the activation of signal transducers and activators of transcription 1 and 3 and induction of cyclooxygenase- 2 after ischemic preconditioning.Circulation 2005;112:1971-1978.

-18 Wolfrum S, Schneider K, Heidbreder M, Nienstedt J, Dominiak P, Dendorfer A: Remote preconditioning protects the heart by activating myocardial PKCepsilon-isoform. Cardiovasc Res 2002;55:583-589.

19 Vahlhaus C, Schulz R, Post H, Onallah R, Heusch G: No prevention of ischemic preconditioning by the protein kinase C inhibitor staurosporine in swine. Circ Res 1996;79:407-414.

-20 Xuan YT, Guo Y, Zhu Y, Wang OL, Rokosh G, Bolli R: Endothelial nitric oxide synthase plays an obligatory role in the late phase of ischemic preconditioning by activating the protein kinase $C$ epsilon p44/42 mitogenactivated protein kinase pSer-signal transducers and activators of transcription1/3 pathway. Circulation 2007;116:535-544.

21 Batarseh A, Li J, Papadopoulos V: Protein kinase C epsilon regulation of translocator protein (18 kDa) Tspo gene expression is mediated through a MAPK pathway targeting STAT3 and c-Jun transcription factors. Biochemistry 2010;49:4766-4778.

-22 Malhotra A, Reich D, Reich D, Nakouzi A, Sanghi V, Geenen DL, Buttrick PM: Experimental diabetes is associated with functional activation of protein kinase $\mathrm{C}$ epsilon and phosphorylation of troponin I in the heart, which are prevented by angiotensin II receptor blockade. Circ Res 1997;81:1027-1033. 
Wang et al.: Repeated Non-Invasive Limb Ischemic Preconditioning Confers Protection in Diabetes

23 Ikeda Y, Olsen GS, Ziv E, Hansen LL, Busch AK, Hansen BF, Shafrir E, Mosthaf-Seedorf L: Cellular mechanism of nutritionally induced insulin resistance in Psammomys obesus: overexpression of protein kinase Cepsilon in skeletal muscle precedes the onset of hyperinsulinemia and hyperglycemia. Diabetes 2001;50:584-592.

24 Hong EG, Jung DY, Ko HJ, Zhang Z, Ma Z, Jun JY, Kim JH, Sumner AD, Vary TC, Gardner TW, Bronson SK, Kim JK: Nonobese, insulin-deficient Ins2Akita mice develop type 2 diabetes phenotypes including insulin resistance and cardiac remodeling. Am J Physiol Endocrinol Metab 2007;293:E1687-1696.

25 Li H, Yao W, Liu Z, Xu A, Huang Y, Ma XL, Irwin MG, Xia Z: Hyperglycemia Abrogates Ischemic Postconditioning Cardioprotection by Impairing AdipoR1/Caveolin-3/STAT3 Signaling in Diabetic Rats. Diabetes 2016;65:942-955.

-26 Akbarzadeh A, Norouzian D, Mehrabi MR, Jamshidi Sh, Farhangi A, Verdi AA, Mofidian SM, Rad BL: Induction of diabetes by Streptozotocin in rats. Indian J Clin Biochem 2007;22:60-64.

27 Li H, Liu Z, Wang J, Wong GT, Cheung CW, Zhang L, Chen C, Xia Z, Irwin MG: Susceptibility to myocardial ischemia reperfusion injury at early stage of type 1 diabetes in rats. Cardiovasc Diabetol 2013;12:133.

28 Mao X, Wang T, Liu Y, Irwin MG, Ou JS, Liao XL, Gao X, Xu Y, Ng KF, Vanhoutte PM, Xia Z: N-acetylcysteine and allopurinol confer synergy in attenuating myocardial ischemia injury via restoring HIF-1alpha/HO-1 signaling in diabetic rats. PLoS One 2013;8:e68949.

29 Hougaard KD, Hjort N, Zeidler D, Sorensen L, Norgaard A, Hansen TM, von Weitzel-Mudersbach P, Simonsen CZ, Damgaard D, Gottrup H, Svendsen K, Rasmussen PV, Ribe LR, Mikkelsen IK, Nagenthiraja K, Cho TH, Redington AN, Botker HE, Ostergaard L, Mouridsen K, Andersen G: Remote Ischemic Perconditioning as an Adjunct Therapy to Thrombolysis in Patients With Acute Ischemic Stroke: A Randomized Trial. Stroke 2014;45:159-167

-30 Stottrup NB, Contractor H, Hyldebrandt JA, Johannsen M, Pedersen CM, Birkler R, Ashrafian H,Sorensen KE, Kharbanda RK, Redington AN, Botker HE: Remote ischemic preconditioning impairs ventricular function and increases infarct size after prolonged ischemia in the isolated neonatal rabbit heart. J Thorac Cardiovasc Surg 2014;147:1049-1055.

-31 Liu Y, Jin J, Qiao S, Lei S, Liao S, Ge ZD, Li H, Wong GT, Irwin MG, Xia Z: Inhibition of PKCbeta2 overexpression ameliorates myocardial ischaemia/reperfusion injury in diabetic rats via restoring caveolin-3/Akt signaling. Clin Sci (Lond) 2015;129:331-344.

32 Soetikno V, Sari FR, Sukumaran V, Lakshmanan AP, Mito S, Harima M, Thandavarayan R A, Suzuki K, Nagata M, Takagi R, Watanabe K: Curcumin prevents diabetic cardiomyopathy in streptozotocin-induced diabetic rats: possible involvement of PKC-MAPK signaling pathway. Eur J Pharm Sci 2012;47:604-614.

33 Xia Z, Kuo KH, Nagareddy PR, Wang F, Guo Z, Guo T, Jiang J, McNeill JH: N-acetylcysteine attenuates PKCbeta2 overexpression and myocardial hypertrophy in streptozotocin-induced diabetic rats. Cardiovasc Res 2007;73:770-782.

34 Simkhovich BZ, Przyklenk K, Kloner RA: Role of protein kinase C in ischemic "conditioning": from first evidence to current perspectives. J Cardiovasc Pharmacol Ther 2013;18:525-532.

35 Mitasikova M. Lin H, Soukup T, Imanaga I, Tribulova N: Diabetes and thyroid hormones affect connexin-43 and PKC-epsilon expression in rat heart atria. Physiol Res 2009;58:211-217.

-36 Banerjee A, Gamboni-Robertson F, Mitchell MB, Rehring TF, Butler K, Cleveland J, Meldrum DR, Shapiro JI Meng XZ: Stress-induced cardioadaptation reveals a code linking hormone receptors and spatial redistribution of PKC isoforms. Ann N Y Acad Sci 1996;793:226-239.

-37 Cosentino-Gomes D, Rocco-Machado N, Meyer-Fernandes JR: Cell Signaling through Protein Kinase C Oxidation and Activation. Int J Mol Sci 2012;13:10697-10721.

38 Kabir AM, Clark JE, Tanno M, Cao X, Hothersall JS, Dashnyam S, Gorog DA, Bellahcene M, Shattock MJ, Marber MS: Cardioprotection initiated by reactive oxygen species is dependent on activation of PKCepsilon. Am J Physiol Heart Circ Physiol 2006;291:H1893-1899.

-39 Boengler K, Hilfiker-Kleiner D, Drexler H, Heusch G, Schulz R: The myocardial JAK/STAT pathway: from protection to failure. Pharmacol Ther 2008;120:172-185.

40 O’Sullivan KE, Breen EP, Gallagher HC, Buggy DJ, Hurley JP: Understanding STAT3 signaling in cardiac ischemia. Basic Res Cardiol 2016;111:27.

41 Heusch G, Musiolik J, Gedik N, Skyschally A: Mitochondrial STAT3 activation and cardioprotection by ischemic postconditioning in pigs with regional myocardial ischemia/reperfusion. Circ Res 2011;109:13021308. 


\section{Cellular Physiology Cell Physiol Biochem 2018;45:2107-2121

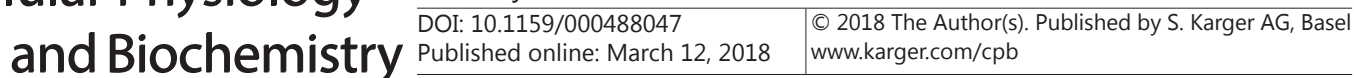 \\ Wang et al.: Repeated Non-Invasive Limb Ischemic Preconditioning Confers Protection \\ in Diabetes}

-42 Boengler K, Ungefug E, Heusch G, Schulz R: The STAT3 inhibitor stattic impairs cardiomyocyte mitochondrial function through increased reactive oxygen species formation. Curr Pharm Des 2013;19:6890-6895.

43 Boengler K, Hilfiker-Kleiner D, Heusch G, Schulz R: Inhibition of permeability transition pore opening by mitochondrial STAT3 and its role in myocardial ischemia/reperfusion. Basic Res Cardiol 2010;105:771785.

44 Kim EJ, Raval AP, Perez-Pinzon MA: Preconditioning mediated by sublethal oxygen-glucose deprivationinduced cyclooxygenase-2 expression via the signal transducers and activators of transcription 3 phosphorylation. J Cereb Blood Flow Metab 2008;28:1329-1340.

-45 Basu A, Sivaprasad U: Protein kinase Cepsilon makes the life and death decision. Cell Signal 2007;19:16331642.

46 Hildebrandt HA, Kreienkamp V, Gent S, Kahlert P, Heusch G, Kleinbongard P: Kinetics and Signal Activation Properties of Circulating Factor(s) From Healthy Volunteers Undergoing Remote Ischemic PreConditioning. JACC Basic Transl Sci 2016;1:3-13.

-47 Boengler K, Buechert A, Heinen Y, Roeskes C, Hilfiker-Kleiner D, Heusch G, Schulz R: Cardioprotection by ischemic postconditioning is lost in aged and STAT3-deficient mice. Circ Res 2008;102:131-135.

48 Gao S, Zhan L, Yang Z, Shi R, Li H, Xia Z, Yuan S, Wu QP, Wang T, Yao S: Remote Limb Ischaemic Postconditioning Protects Against Myocardial Ischaemia/Reperfusion Injury in Mice: Activation of JAK/ STAT3-Mediated Nrf2-Antioxidant Signalling. Cell Physiol Biochem 2017;43:1140-1151.

49 Wu Q, Wang T, Chen S, Zhou Q, Li H, Hu N, Feng Y, Dong N, Yao S, Xia Z: Cardiac protective effects of remote ischaemic preconditioning in children undergoing tetralogy of fallot repair surgery: a randomized controlled trial. Eur Heart J 2017;0:1-11

-50 Hilfiker-Kleiner D, Kaminski K, Podewski E, Bonda T, Schaefer A, Sliwa K, Forster O, Quint A, Landmesser U, Doerries C, Luchtefeld M, Poli V, Schneider MD, Balligand JL, Desjardins F, Ansari A, Struman I, Nguyen NQ Zschemisch NH, Klein G, Heusch G, Schulz R, Hilfiker A, Drexler H: A cathepsin D-cleaved $16 \mathrm{kDa}$ form of prolactin mediates postpartum cardiomyopathy. Cell 2007;128:589-600.

51 Muller J, Gorressen S, Grandoch M, Feldmann K, Kretschmer I, Lehr S, Ding Z, Schmitt JP, Schrader J, Garbers C, Heusch G, Kelm M, Scheller J, Fischer JW: Interleukin-6-dependent phenotypic modulation of cardiac fibroblasts after acute myocardial infarction. Basic Res Cardiol 2014;109:440. 